\title{
International Market Structuring with a Multinational Enterprise
}

\author{
Sukwhan Ahn \\ Sookmyung Women's University \\ In Soo Kang \\ Sookmyung Women's U niversity \\ Hyukseung Shin \\ Sookmyung Women's University
}

\begin{abstract}
This paper examines the economic rationales and conditions for the emer gence of multinational enterprises ( M NEs). Promoting production efficiency is not sufficient to justify the emergence of an M NE. With taxes in the model, tax authorities heavily tax an M NE's economic activities, in which case an M NE becomes harder to justify on welfare grounds. This arises from the public good nature of MNEs and suggests a tax policy coordination to foster welfare improvement through the emergence of MNEs. (JEL: F23, D43, H21)
\end{abstract}

* Correspondence Address: Sukwhan Ahn, Department of Economics, Sookmyung Women's U niversity, 53-12 Chungpa-D ong 2 Ka, Yongsan-K u, Seoul 140-742, Korea, (Tel) 82-2-710-9502, (Fax) 82-2-718-2337, (Email) swahn@sookmyung.ac.kr; In Soo Kang, Department of International Trade, Sookmyung Women's University; Hyukseung Shin, Department of Consumer E conomics, Sookmyung Women's University; This research was conducted by 1996 Sookmyung Women's University research grant. We are entirely grateful to one of the referees for penetrating and constructive suggestions. A usual disclaimer applies.

(C1997 - Institute for International Economics, Sejong Institution. All rights reserved. 


\section{Introduction}

As practices and theories of multinational enterprises (M NEs, hereafter) have thrived over the past decades, many economic cases for M NEs have been brought forth in several strands. In the economic and business literature, MNEs are normally recognized as the seekers of natural resources, product markets, efficiency, or strategic asset/ capabilities. ${ }^{1} \mathrm{~F}$ rom the standpoint of positive economics, the flourishing of M NEs worldwide calls for an investigation to see if the emergence and behavior of these organizations are justified on efficiency grounds. M otivated by this observation, this paper examines a case in which a firm of one country merges for efficiency reasons with a firm of another country complementary in some production features. ${ }^{2}$ With the amalgamation of complementary firms being understood as motivated by the promotion of the efficiency in production, this paper may well be deemed dealing with the efficiency argument for M NEs from a narrow perspective.

From a broader point of view, however, it takes only a short step to realize that many other arguments for MNEs are driven by the same economic force that is captured by the simple model presented in this paper. Stated differently, many rationales for the existence and behavior of M NEs affect corporate performances by the promotion of production efficiency. For instance, natural resources that MNEs look for include not only various kinds of physical resources and labor but also technological capability, management or marketing expertise and organizational skills. Clearly, these are all particular efforts to increase the efficiency of corporate behavior. Strategic actions by an M NE are nothing other than its efforts to put itself at an advantageous position in competition with other firms. ${ }^{3} \mathrm{M}$ ore often than not, these efforts would have no economic effects on corporate performances if they failed to promote efficiency. Noting that many rationales made for MNEs boil down to an efficiency argument, this paper assesses the economic consequences of M NEs in a simple model which treats M NES

1. See Behrman [1972].

2. These features cover a wide range of elements affecting production: including factor endowments, technical advantages, cultures, institutional arrangements, economic systems and policies, and market structures. 
as entities that are created to exploit efficiency in production. In particular, this study captures the efficiency enhancing attribute of M NEs in the form of cost reduction associated with the emergence or activity of M NEs. ${ }^{4}$

For a proper investigation of economic consequences of M NEs, it is misleading to look at only the production side of an economy. The welfare of an economy may fall even when the emergence of behavior of MNES increases production efficiency, and thus, an economy has to consider the consumption side as well as the production side in its welfare consideration. Basically, this inadequacy of production efficiency as a welfare measure arises from the fact that the promotion of production efficiency from the firms' viewpoint is not incompatible with the market structure growing less competitive. ${ }^{5} \mathrm{~F}$ or instance, a market environment with firms seeking to take a strategic vintage point creates in most cases a more concentrated market structure. In the similar vein, a proliferation of MNEs normally implies a market structure characterized by fewer firms larger in size, thereby the market structure being more concentrated. Changes in market structure in the presence of MNEs are the distinguishing feature that this paper explicitly incorporates. Specifically, this study clearly shows that the emergence of MNEs creates a gain in production efficiency which has to be weighed against a potential loss in welfare from the consumption side. Accordingly, the presence of MNEs that are superior in terms of production efficiency does not necessarily guarantee the improvement of welfare in an economy.

This paper is organized as follows. In section II, the basic model is introduced. Section III examines the case in which the emergence of an M NE is justified on welfare grounds. In section IV, the government tax policies are

3. Strategic actions include a collaborative alliance in production and $R \backslash \& D$, a vertical integration with upstream or downstream firms, or a wide range of economies of scopes.

4. M arket-seeking behavior of an M NE can be modeled in a setting in which there is a rise in demand with the MNE's cost structure remaining unchanged. This modeling brings about qualitatively the same results as the model of this paper in which demand stays the same with costs of production being reduced in the presence of an MNE.

5. See Dunning [1992] for many realistic incidents on this. 
introduced. The emergence of an MNE alters each government's taxing position and in this strategic circumstance, the welfare justification for an MNE is shown to be harder to obtain. Section 5 concludes.

\section{The Model}

Consider a two-country, one-industry model. The two countries are $\mathcal{A}$ and $Z$, each of which has a monopoly firm in the industry. The monopoly firm in country $\mathrm{i}$ is denoted by $\mathcal{F}_{\mathrm{i}}$ for $\mathrm{i}=\mathcal{A}, Z$. These two firms $\mathcal{F}_{\mathcal{A}}$ and $\mathcal{F}_{Z}$ are assumed to be the only suppliers of the product in the international market. Production in this industry is divided into two processes, 1 and 2. The technology of the two firms for both processes are represented by constant marginal costs with zero fixed cost. In particular, firm $\mathcal{F}_{\mathscr{A}}$ exhibits a technology in which the marginal cost is low, denoted by $\underline{c}$, for process 1 and high, denoted by $c_{-}$, for process 2. Obviously, $c_{-}>\underline{c}$ and let $\Delta \mathrm{c}$ the difference: that is, $\Delta \mathrm{C}=\mathrm{C}_{-}-$ c. For firm $\mathcal{F}_{z}$, the cost structure is reversed: that is, its marginal cost is $\underline{c}$ for process 2 and $C_{-}$for process 1 . The international demand function for the product is $P(X)=\alpha-\beta X$. It is assumed that $\alpha>c_{-}+\underline{c}$ and $\beta>0$ : that is, the demand for the product is adequately large and the demand schedule is negatively sloped. Let $P\left(X_{i}\right)=\alpha-\left(\beta / \Sigma_{i}\right) X_{i}$ be country $i$ 's inverse demand function for the product for $\mathrm{i}=\mathcal{A}, Z$. where $\Sigma_{\mathrm{i}}>0$ and $\Sigma_{\mathscr{A}}+\Sigma_{Z} \leq 1$. $^{6}$

\section{A Case for a Multinational Enterprise}

Consider the duopoly Cournot equilibrium in the international market. Each monopoly firm $\mathcal{F}_{\text {i }}$ solves

$$
\max _{X_{i}} X_{i}\left\{-\left(X_{i}+X_{j}\right)\right\}-(\bar{C}+\underline{c}) X_{i} \text { given } X_{j} \text {. }
$$

Let $X_{i}^{c}$ be the output level chosen by firm $i$ and $\Pi_{i}^{c}$ be the profit accrued to firm $i$ at the Cournot equilibrium. The Cournot equilibrium is characterized in the following Lemma 1.

6. $\Sigma_{\mathcal{A}}+\Sigma_{z}=1$ represents the case in which the product of this industry is demanded only by the two countries in the model. $\Sigma_{\mathcal{A}}+\Sigma_{z}<1$ reflects the circumstance in which there are countries other than $\mathcal{A}$ and $z$ which demand the product. 
Lemma 1: At the duopoly Cournot equilibrium, it holds that

(i) $\mathrm{X}_{\mathrm{i}}^{\mathrm{c}}=\left[\alpha-\left(\mathrm{C}_{-}+\underline{\mathrm{c}}\right)\right] / 3 \beta$ for $\mathrm{i}=\mathcal{A}, Z$ and $\mathrm{X}^{\mathrm{c}}=2\left[\alpha-\left(\mathrm{C}_{-}+\underline{\mathrm{c}}\right)\right] / 3 \beta$ where $X^{c}=X_{A}^{c}+X_{z}^{c}$;

(ii) $\Pi_{\mathrm{i}}^{\mathrm{c}}=\left[\alpha-\left(\mathrm{c}_{-}+\underline{\mathrm{c}}\right)\right]^{2} / 9 \beta$ for $\mathrm{i}=\mathcal{A}, Z_{\text {; }}$

(iii) $P\left(X^{c}\right)=\left[\alpha+2\left(c_{-}+\underline{c}\right)\right] / 3$.

Proof: The first-order conditions imply $X_{i}=\left[\alpha-\left(c_{-}+\underline{c}\right)-\beta X_{j}\right] / 2 \beta$ for $\mathrm{i}, \mathrm{j}=\mathcal{A}$, $Z$. Solving these conditions simultaneously and using the demand functions give the results.

Consider the economic consequences of the emergence of an MNE, denoted by $\mathcal{F}_{\mathcal{g Z}}$, which is the entity that comes into being through the merger of $\mathcal{F}_{\mathcal{A}}$ and $\mathcal{F}_{\mathcal{Z}}$. The MNE $\mathcal{F}_{\mathscr{A} Z}$ exhibits a technology superior to both $\mathcal{F}_{\mathcal{A}}$ and $\mathcal{F}_{z}$ by being able to operate processes 1 and 2 with the low marginal cost of c. Being the monopolist in the international market for this product, $\mathcal{F}_{\text {gz }}$ solves the following problem:

$$
\max _{X} X(-X)-2 c x .
$$

Let $\Theta_{i}$ be the countr y i's ownership fraction of $\mathcal{F}_{\mathscr{A}}$ in the following sense: of $\mathrm{X}^{\mathrm{m}}$, the output produced by $\mathcal{F}_{\mathcal{g Z}}, \Theta_{\mathrm{i}} \mathrm{X}^{\mathrm{m}}$ belongs to countr $\mathrm{y}$ i for $\mathcal{A}, Z$. Obviously, $\Theta_{\mathrm{i}}>0$ for $\mathrm{i}=1,2$ and $\Theta_{\mathfrak{A}}+\Theta_{z}=1$. Let $\Pi_{\mathrm{i}}^{\mathrm{m}}$ be the profit accrued to country $i$ and $P\left(X^{m}\right)$ be the price at the equilibrium with the $M N E$. The following Lemma 2 presents the results in case the M NE emerges.

Lemma 2. Suppose that $\mathcal{F}_{\mathscr{Y}}$ and $\mathcal{F}_{\mathcal{Z}}$ merge into the MNE $\mathcal{F}_{\mathscr{Y} Z}$ of which country $\mathrm{i}$ holds the fraction $\Theta_{\mathrm{i}}$ of ownership ( where $\mathrm{i}=\mathcal{A}, Z$ ). Then it follows that

(i) $\Pi_{i}^{m}=\Theta_{i} \Pi^{m}$ where $\Pi^{m}=(\alpha-2 \underline{c})^{2} / 4 \beta$;

(ii) $\mathrm{P}\left(\mathrm{X}^{\mathrm{m}}\right)=(\alpha+2 \underline{\mathrm{c}}) / 2$.

Proof: The output level $\mathcal{F}_{\text {gz }}$ chooses, denoted by $X^{m}$, is $(\alpha-2 \underline{c}) / 2 \beta$, and thus the profit to $\mathcal{F}_{\text {IZ }}$, denoted by $\Pi^{\mathrm{m}}$ is $(\alpha-2 \mathrm{c})^{2} / 4 \beta$. The rest are straightforward.

For instance, in a symmetric case in which $\Theta_{\Re}=\Theta_{z}=1 / 2$, the profit accrued to each country is $\Pi_{\mathscr{A}}^{\mathrm{m}}=\Pi_{z}^{\mathrm{m}}=(\alpha-2 \underline{c})^{2} / 8 \beta$. The ensuing Theorem 1 indicates that ownership division affects the profit prospects of $\mathcal{F}_{\mathcal{A}}$ and $\mathcal{F}_{\mathcal{Z}}$ after merger. 
Theorem 1: $\Pi_{i}^{c}<\Pi_{i}^{m}$ if and only if $\Theta_{i}>4\{\alpha-(\underline{c}+\underline{c})]^{2} / 9(\alpha-2 \underline{c})^{2}$ for $i=\mathcal{A}, Z$.

Proof: It is straightforward to see this by rearranging $\Theta_{i}(\alpha-2 \underline{c})^{2} / 4 \beta>[\alpha-$ $(c+\underline{c})]^{2} / 9 \beta$.

To make the case more realistically convincing, in what follows, it is assumed that the emergence of the MNE increases the profits that accrue to the claim holders to firms $\mathcal{F}_{\mathcal{A}}$ and $\mathcal{F}_{Z}$ : otherwise, the birth of the M NE could not be agreed upon and pursued by these firms. This spirit is brought into the model through Assumption 1.

Assumption 1: The ownership of the MNE is divided between the two coun tries such that $\Theta_{\mathrm{i}}>4[\alpha-(\mathrm{c}+\underline{\mathrm{c}})]^{2} / 9(\alpha-2 \underline{\mathrm{c}})^{2}$ for $\mathrm{i}=\mathcal{A}, Z$.

Profits are not unaptly considered only an incomplete measure of the welfare change emanating from the emergence of the M NE as it does not incorporate the consumer side of an economy in welfare assessment. In this regard, Theorem 1 needs to be extended. A widely adopted criterion for welfare assessment is total surplus (that is, the sum of consumer's surplus and producer's surplus). Let $C S_{i}^{c}$ be the consumer's surplus of country $i$ at the duopoly Cournot equilibrium, and similarly $\mathrm{CS}_{i}^{\mathrm{m}}$ be that with the M NE where $\mathrm{i}=\mathcal{A}, Z$. Let $\mathrm{X}_{\mathrm{i}}^{\text {cd }}$ be the quantity of the product that is demanded by consumers in country $i$ at the Cournot equilibrium. Similarly, $X_{i}^{m d}$ denotes the quantity demanded by consumers in country $i$ in the presence of the MNE. Then

$$
\mathrm{CS}_{\mathrm{i}}^{\mathrm{c}}=\int_{0}^{\mathrm{X}_{\mathrm{i}}^{\mathrm{cd}}}\left[-\left(/ \Sigma_{\mathrm{i}}\right) \mathrm{X}_{\mathrm{i}}-\mathrm{P}\left(\mathrm{X}^{\mathrm{c}}\right)\right] \mathrm{dX_{i }}=2 \Sigma_{\mathrm{i}}[-(\underline{\mathrm{c}}+\overline{\mathrm{C}})]^{2} / 9
$$

where $\mathrm{e}^{\mathrm{cd}}=2 \Sigma_{\mathrm{i}}[\alpha-(\underline{\mathrm{c}}+\mathrm{c} \underline{\mathrm{c}}] / 3 \beta$ and

$$
\left.\mathrm{CS}_{i}^{\mathrm{m}}=\int_{0}^{\mathrm{X}_{\mathrm{i}}^{\mathrm{md}}}\left[-\left(/ \Sigma_{\mathrm{i}}\right) \mathrm{X}_{\mathrm{i}}-\mathrm{P}\left(\mathrm{X}^{\mathrm{m}}\right)\right] \mathrm{dX_{i }}=\Sigma_{\mathrm{i}}(-2 \mathrm{c})\right]^{2} / 8
$$

where ${ }^{8} X_{i}^{m d}=\Sigma_{i}(\alpha-2 \underline{c}) / 2 \beta$. Let $W_{i}^{c}$ be the total surplus of country $i$ at the duopoly Cournot equilibrium where $\mathrm{i}=\mathcal{A}, Z$. Then

7. $X_{i}^{c d}$ is defined $\alpha-\left(\beta / \Sigma_{i}\right) X_{i}^{c d}=P\left(X^{c}\right)$.

8. $X_{i}^{\text {md }}$ is defined $\alpha-\left(\beta / \Sigma_{i}\right) X_{i}^{\text {md }}=P\left(X^{m}\right)$. 


$$
W_{i}^{c}=C S_{i}^{c}+\mathrm{I}_{i}=\left(1+2 \Sigma_{i}\right)[-(\bar{c}+\underline{c})]^{2} / 9
$$

for $\mathrm{i}=\mathcal{A}, Z$. Let $\mathrm{w}_{\mathrm{i}}{ }^{\mathrm{m}}$ be the total surplus of country $\mathrm{i}$ when $\mathcal{F}_{\mathcal{R}}$ and $\mathcal{F}_{\mathcal{Z}}$ merge into $\mathcal{F}_{\mathcal{A} Z}$ where $\mathrm{i}=\mathcal{A}, Z$. Then

$$
\mathrm{W}_{\mathrm{i}}^{\mathrm{m}}=\mathrm{CS}_{\mathrm{i}}^{\mathrm{m}}+\mathrm{Ii}_{\mathrm{i}}^{\mathrm{m}}=\left(\Sigma_{\mathrm{i}}+2 \Theta_{\mathrm{i}}\right)(-2 \underline{\mathrm{c}})^{2} / 8
$$

where $X_{i}^{m}=\Theta_{i} X^{m}$ for $i=\mathcal{A}, Z$. The following theorem specifies the condition under which the emergence of the productively more efficient M NE is justified on welfare grounds.

Theorem 2: $\mathrm{W}_{i}^{\mathrm{m}}>\mathrm{W}_{\mathrm{i}}^{\mathrm{c}}$ if and only if $\Delta \mathrm{c}>(\alpha-2 \mathrm{c})\left[\Gamma\left(\Sigma_{i}, \Theta_{\mathrm{i}}\right)-1\right] / \Gamma\left(\Sigma_{\mathrm{i}}, \Theta_{\mathrm{i}}\right.$ where $\Gamma\left(\Sigma_{i}, \Theta_{\mathrm{i}}\right)=\left[2 \sqrt{2\left(1+2 \Sigma_{\mathrm{i}}\right)} / 3 \sqrt{\Sigma_{\mathrm{i}}+2 \Theta_{\mathrm{i}}}\right]$ for $\mathrm{i}=\mathcal{A}, Z$.

Proof: By definition, $\mathrm{W}_{\mathrm{i}}{ }^{\mathrm{C}}<\mathrm{W}_{\mathrm{i}}{ }^{\mathrm{m}}$ is equivalent to $\left\{(\alpha-2 \underline{\mathrm{c}}) /\left[\alpha-\left(\mathrm{C}_{-}+\underline{\mathrm{c}}\right)\right]\right\}^{2}<8$ $\left(1+2 \Sigma_{i}\right) / 9\left(\Sigma_{i}+2 \Theta_{i}\right)$. Rearranging terms completes the proof.

Note that $\Gamma\left(\Sigma_{\mathrm{i}}, \Theta_{\mathrm{i}}\right)>1$ if and only if $\Theta_{\mathrm{i}}<7 \Sigma_{\mathrm{i}} / 18+4 / 9$. Hence, if $\Theta_{\mathrm{i}}<7 \Sigma_{\mathrm{i}} / 18$ $+4 / 9$ holds for at least one countr $y$, the condition on cost differential for welfare improvement through the emergence of the MNE is not trivial.

Savings in production cost through merger are necessarily accompanied by a change in market structure towards a less competitive one. According to Theorem 2, only when efficiency gain from cost reduction is sufficiently large can the emergence of an M NE be justified on welfare grounds. In other words, the welfare promotion fostered by cost reduction ought to be weighed against the welfare deterioration caused by less competition between firms, and the condition under which the former effect dominates the latter effect is captured by a sufficient differential in costs. Under Assumption 1, it is true that the producer's surplus is larger with the emergence of the M NE since the producer's surplus is the profit. The question is, then, is it possible that the consumer's surplus increases with the emergence of $\mathcal{F}_{\mathcal{A Z}}$ ? If so, under what condition? This question is addressed in Theorem 3.

Theorem 3: With the emergence of the cost efficient M NE $\mathcal{F}_{\mathrm{Fz}}$, the consumer's surplus becomes greater than without it if and only if $\Delta C>(\alpha-2 \underline{c}) / 4$.

Proof: $\mathrm{CS}_{\mathrm{i}}^{\mathrm{c}}<\mathrm{CS}_{\mathrm{i}}^{\mathrm{m}}$ is equivalent to $9 / 16>\{[\alpha-(\underline{\mathrm{C}} \underline{\mathrm{c}} \underline{\mathrm{c}})] /(\alpha-2 \underline{\mathrm{c}})\}^{2}$.

Certainly, if there exists a condition under which this holds true, then it is 
worth investigating the economic circumstance under which the condition presented in Theorem 3 is sufficient for total surplus to increase. A simple comparison of the two threshold values in Theorems 2 and 3 gives the result as presented in Corollary 1.

Corollary 1: The emergence of the MNE improves a country's welfare (as measured by total surplus) whenever it increases the country's consumer's sur plus provided that the country's ownership fraction of the MNE is not too small.

Proof: By definition, $W_{i}^{m}>W_{i}^{c}$ is equivalent to $9\left(\Sigma_{i}+2 \Theta_{i}\right) / 8\left(1+2 \Sigma_{i}\right)>\{[\alpha-$ $(\mathrm{c}+\underline{c})] /(\alpha-2 \underline{c})\}^{2}$ and similarly, by definition, $\mathrm{CS}_{i}^{\mathrm{m}}>\mathrm{CS}_{\mathrm{i}}^{\mathrm{c}}$ if and only if $9 / 16>$ $\{[\alpha-(c+\underline{c})] /(\alpha-2 \underline{c})\}^{2}$. Note that $9\left(\Sigma_{i}+2 \Theta_{\mathrm{i}}\right) / 8\left(1+2 \Sigma_{\mathrm{i}}\right)>9 / 16$ is equivalent to $\Theta_{\mathrm{i}}>1 / 4$.

In this paper, the ownership fraction $\Theta_{i}$ is exogenously given. If $\Theta_{i}$ is small, thus, then country i's producer's surplus with the creation of the MNE may well be less than that without the forming of the MNE. In case $\Theta_{i}$ is very small, an increase in country i's consumer's surplus may not be sufficient to raise its total surplus because the reduction in its producer's surplus is too large. ${ }^{9}$

\section{Strategic Tax Policy}

Even when the cost differential $\Delta \mathrm{c}$ is large enough to justify the amalgamation of $\mathcal{F}_{\mathcal{A}}$ and $\mathcal{F}_{\mathcal{Z}}$ on welfare grounds, it stands a reason to suspect that both countries may become worse off in a strategic environment in which there are policy variables countries have in their control. In this section, an investigation is conducted to see if the introduction of an excise tax can jeopardize the birth of a welfare enhancing M NE. The scenario adopted in this section is that governments are able to act first, and firms decide on output levels with these tax rates as being given. Governments understand how tax rates will influence the output equilibrium and they will take this information into account when they choose their tax rates in the Cournot

9. In the symmetric case in which $\Theta_{\mathfrak{A}}=\Theta_{z}=1 / 2$, an increase in country i 's consumer's surplus is a sufficient condition for an increase in the country's welfare. 
tax rate game between themselves. Therefore, subgame perfect equilibrium is a relevant solution concept and thus used in this section. ${ }^{10}$

Quite often, working with the general model to draw implications involves unnecessarily cumbersome complications without rendering richer insights. This is true of this section and thus the following expository tactics is adopted here: (i) in establishing the framework, the general model is employed, and (ii) in drawing implications from the framework, a special case is examined. To be specific, this paper investigates the symmetric case to obtain implications of strategic tax policy on the emergence of MNE. Therefore, the first part of this section is devoted to the general case followed by the second part dealing with the symmetric case.

Let $\mathrm{T}_{i}$ be the tax rate of excise taxation that country $\mathrm{i}$ (where $\mathrm{i}=\mathcal{A}, Z \mathrm{im}$ poses on the production activity that the M NE carries out in its jurisdiction. In what follows, $Y\left(T_{\mathscr{A}}, T_{Z}\right)$ denotes the value of $Y$ when country $i$ sets the tax rate at $\mathrm{T}_{\mathrm{i}}$, for $\mathrm{i}=\mathcal{A}, Z^{11}$

In the absence of an $M N E$, facing $T_{i}$, firm $\mathcal{F}_{i}$ 's problem is

$$
\max _{X_{i}} X_{i}\left\{-\left(X_{i}+X_{j}\right)\right\}-\left[\left(\bar{c}+T_{i}\right)+\left(\underline{c}+T_{i}\right)\right] X_{i} \text { given } X_{j} \text { and } T_{i} \text {. }
$$

At the Cournot output equilibrium between firms under the tax regime represented by $T_{i}$ and $T_{j}, X_{i}^{c}\left(T_{i}, T_{j}\right)$ is the output level chosen by firm $\mathcal{F}_{i}$ and $X_{i}^{c d}\left(T_{i}, T_{j}\right)$ is the quantity demanded by country $i$. Then Lemma 3 follows.

Lemma 3: At the Cournot equilibrium output under the tax regime represent ed by $T_{i}$ and $T_{j}$, the following results are obtain for $\mathrm{i}, \mathrm{j}=\mathcal{A}, Z$.

(i) $X_{i}^{c}\left(T_{i}, T_{j}\right)=\left[\alpha-\left(c_{-}+\underline{c}\right)-2\left(2 T_{i}+T_{j}\right)\right] / 3 \beta$; and $X^{c}\left(T_{i}, T_{j}\right)$

$$
=2\left[\alpha-\left(c_{-}+\underline{c}\right)-3\left(T_{i}+T_{j}\right)\right] / 3 \beta
$$

(ii) $P\left[X^{c}\left(T_{i}, T_{j}\right)\right]=\left[\alpha+2\left(c_{-}+\underline{c}\right)+6\left(T_{i}+T_{j}\right)\right] / 3$

(iii) $X_{i}^{c d}\left(T_{i}, T_{j}\right)=2 \Sigma_{i}\left[\alpha-\left(c_{-}+\underline{c}\right)-3\left(T_{i}+T_{j}\right)\right] / 3 \beta$.

Proof: Similar to Theorem 2.

Let $R_{i}^{c}\left(T_{i}, T_{j}\right)$ denote the government tax revenue under the tax regime represented by $T_{i}$ and $T_{j}$. Country i's welfare $W_{i}^{c}\left(T_{i}, T_{j}\right)$ is defined by

10. See K reps [1990] for $N$ ash equilibrium refinements.

11. For instance, $Y$ can be $X_{i}, X_{i}^{c}, X_{i}^{c d}, X_{i}^{m d}, C S_{i}^{c}, W_{i}^{c}, C S_{i}{ }^{m}, W_{i}^{m}$ and so on for $i=\mathcal{A}, Z$. 


$$
W_{i}^{c}\left(T_{i}, T_{j}\right)=C S_{i}^{c}\left(T_{i}, T_{j}\right)+\Pi_{i}^{c}\left(T_{i}, T_{j}\right)+R_{i}^{c}\left(T_{i}, T_{j}\right)
$$

where

$$
\begin{aligned}
C_{i}^{c}\left(T_{i}, T_{j}\right) & =\int_{0}^{X_{i}^{c d}\left(T_{i}, T_{j}\right)}\left\{P(X)-P\left[X^{c}\left(T_{i}, T_{j}\right)\right]\right\} d X \\
& =2 \Sigma_{i}\left[-(\bar{c}+\underline{c})-3\left(T_{i}+T_{j}\right)\right]^{2} / 9 ; \\
\Pi_{i}^{c}\left(T_{i}, T_{j}\right) & =\left\{P\left[X^{c}\left(T_{i}, T_{j}\right)\right]-\left[\left(\bar{C}+T_{i}\right)+\left(\underline{c}+T_{i}\right)\right]\right\} X_{i}^{c}\left(T_{i}, T_{j}\right) \\
& =\left[-(\bar{c}+\underline{c})+6\left(T_{i}+T_{j}\right)\right]\left[-(\bar{c}+\underline{c})-2\left(2 T_{i}+T_{j}\right)\right] \\
R_{i}^{c}\left(T_{i}, T_{j}\right) & =2 T_{i} X_{i}^{c}\left(T_{i}, T_{j}\right) \\
& =2 T_{i}\left[-(\bar{c}+\underline{c})-2\left(2 T_{i}+T_{j}\right)\right] / 3
\end{aligned}
$$

for $\mathrm{i}, \mathrm{j}=\mathcal{A}, Z$. It is immediate to have

$$
\begin{aligned}
& W_{i}^{c}\left(T_{i}, T_{j}\right)=2 \Sigma_{i}\left[-(C+\underline{c})-3\left(T_{i}+T_{j}\right)\right]^{2} / 9 \\
& \quad+\left[-(C+\underline{c})+6\left(T_{i}+T_{j}\right)\right]\left[-(C+\underline{c})-2\left(2 T_{i}+T_{j}\right)\right] / 9 .
\end{aligned}
$$

The welfare maximizing tax rate by the government of country $i$ is chosen by setting $d W_{i}^{c}\left(T_{i}, T_{j}\right) / d T_{i}$ equal to zero: that is, the government i's reaction function is given by

$$
\mathrm{T}_{\mathrm{i}}^{\mathrm{c}}\left(\mathrm{T}_{\mathrm{j}}\right)=\frac{\left(1-6 \Sigma_{\mathrm{i}}\right)[-(\overline{\mathrm{c}}+\underline{\mathrm{c}})] \Sigma_{\mathrm{i}}}{6\left(4-3 \Sigma_{\mathrm{i}}\right)}-\frac{3\left(1-\Sigma_{\mathrm{i}}\right)}{\left(4-3 \Sigma_{\mathrm{i}}\right)} \mathrm{T}_{\mathrm{j}}
$$

for $\mathrm{i}, \mathrm{j}=\mathcal{A}, Z$. By solving these two reaction functions simultaneously, the Cournot equilibrium tax rates $\left(\mathrm{T}_{\mathscr{A}}^{c}, \mathrm{~T}_{\mathcal{Z}}^{\mathrm{c}}\right)$ are obtained:

$$
\left.\mathrm{T}_{\mathrm{i}}^{\mathrm{c}}=\frac{\left(1-21 \Sigma_{\mathrm{i}}+15 \Sigma_{\mathrm{j}}\right)}{6\left(7-3 \Sigma_{\mathrm{i}}-3 \Sigma_{\mathrm{i}}\right)}[-(\overline{\mathrm{c}}+\underline{\mathrm{c}}))\right]
$$

for $\mathrm{i}, \mathrm{j}=\mathcal{A}, Z$. The Cournot equilibrium tax rates in (7) possess the property presented in the ensuing Theorem 4.

Theorem 4: $\mathrm{T}_{\mathrm{i}}^{\mathrm{c}}>0$ and $\mathrm{T}_{\mathrm{j}}^{\mathrm{c}}>0$ (where $\mathrm{i}, \mathrm{j}=\mathcal{A}, Z$ ) are feasible when the demand of $\mathcal{A}$ and $Z$ (that is, the two countries supplying the product) for the product is weak.

Proof: For $\mathrm{i}, \mathrm{j}=\mathcal{A}, Z, \mathrm{~T}_{\mathrm{i}}^{\mathrm{c}}>0$ holds if and only if $\Sigma_{\mathrm{i}}<\left(1+15 \Sigma_{\mathrm{j}}\right) / 21$, which is equivalent to $\Sigma_{\mathrm{i}}<1 / 6$.

Theorem 4 clearly shows that the result of this paper can be differentiated 
from that of Brander and Spencer [1985] and many others in that in this paper taxation, as opposed to subsidization, can be the governments' equilibrium choices. In Brander and Spencer [1985], countries subsidize their firms with a view to putting their firms at an advantageous position in competition with foreign firms. However, their finding does take account of the consumption side in welfare assessment and only considers the production side of an economy. This study adopts a more general approach for welfare assessment, and finds that the result of the Brander-Spencer kind may not hold true for cases in which the countries supplying the product take only a meager share in demanding the product. If the demand of the producing countries for the product is quite small relative to their supply to the market, they are not concerned about their consumer's surpluses being reduced by imposition of taxes. Rather, in this case, they will likely gain from the taxes since tax revenue more than offsets the negative effect of the taxes on consumer's surplus. It should be emphasized that this finding cannot be made from models that dispense with the consumption side.

With the government of the two countries exercising the Cournot equilibrium tax policies, the welfare of country $i$ becomes

$$
W_{i}^{c}\left(T_{i}^{c}, T_{j}^{c}\right)=\Psi\left(\Sigma_{i}, \Sigma_{j}\right)[-(\bar{C}+\underline{c})]^{2}
$$

where

$$
\Psi\left(\Sigma_{i}, \Sigma_{j}\right)=\frac{2\left[4 \Sigma_{i}+\left(1-\Sigma-\sum\right)\left(4-3 \Sigma_{i}-3 \Sigma_{j}\right)\right]}{\left(7-3 \Sigma_{i}-3 \Sigma_{j}\right)^{2}} .
$$

Obviously, $\Psi\left(\Sigma_{\mathrm{i}}, \Sigma_{\mathrm{j}}\right)>0$.

Now consider the circumstance in which the MNE emerges and the governments of the two countries use tax policies strategically. Recall that superscript $m$ refers to the cases with the MNE. In the following Lemma 4, the output and price levels in the presence of the MNE are given.

Lemma $4:$ In the presence of the MNE, it holds that

(i) $X^{m}\left(T_{i}, T_{j}\right)=X^{m d}\left(T_{i}, T_{j}\right)=\left[(\alpha-2 \underline{c})-\left(T_{i}+T_{j}\right)\right] / 2 \beta$;

(ii) $P\left[X^{m}\left(T_{i}, T_{j}\right)\right]=\left[(\alpha+2 \underline{c})+\left(T_{i}+T_{j}\right)\right] / 2$; 
(iii) $X_{i}^{m d}\left(T_{i}, T_{j}\right)=\sum_{i} X^{m d}\left(T_{i}, T_{j}\right)=\sum_{i}\left[(\alpha-2 \underline{c})-\left(T_{i}+T_{j}\right)\right] / 2 \beta ;{ }^{12}$

(iv) $\Pi_{i}^{m}\left(T_{i}, T_{j}\right)=\Theta_{i} \Pi^{m}\left(T_{i}, T_{j}\right)=\Theta_{i}\left[(\alpha-2 \underline{c})-\left(T_{i}+T_{j}\right)\right]^{2} / 4 \beta$;

Proof: Similar to the proof of Lemma 2.

The welfare of country $i$ in the presence of the M NE is

$$
W_{i}^{m}\left(T_{i}, T_{j}\right)=C S_{i}^{m}\left(T_{i}, T_{j}\right)+\Theta_{i} \Pi^{m}\left(T_{i}, T_{j}\right)+R_{i}^{m}\left(T_{i}, T_{j}\right)
$$

where

$$
\begin{aligned}
C_{i}^{m}\left(T_{i}, T_{j}\right) & =\int_{0}^{X_{i}^{m}\left(T_{i}, T_{j}\right)}\left\{P(X)-P\left[X^{m}\left(T_{i}, T_{j}\right)\right]\right\} d X \\
& =\Sigma_{i}\left[(-2 \underline{c})-\left(T_{i}+T_{j}\right)\right]^{2} / 8 \\
\Pi_{i}^{m}\left(T_{i}, T_{j}\right) & =\Theta_{i} \Pi^{m}\left(T_{i}, T_{j}\right) \\
& =\Theta_{i}\left\{P\left[X^{m}\left(T_{i}, T_{j}\right)\right]-\left[\left(\underline{c}+T_{i}\right)+\left(\underline{c}+T_{j}\right)\right]\right\} X^{m}\left(T_{i}, T_{j}\right) \\
& =\Theta_{i}\left[(-2 \underline{c})-\left(T_{i}+T_{j}\right)\right]^{2} / 4 ; \\
R_{i}^{m}\left(T_{i}, T_{j}\right) & =T_{i} X^{m}\left(T_{i}, T_{j}\right) \\
& =T_{i}\left[(-2 \underline{c})-\left(T_{i}+T_{j}\right) / 2\right.
\end{aligned}
$$

for $\mathrm{i}, \mathrm{j}=\mathcal{A}, Z$. Let $\Omega_{\mathrm{i}} \equiv \Sigma_{\mathrm{i}}+2 \Theta_{\mathrm{i}}$. Then, for $\mathrm{i}, \mathrm{j}=\mathcal{A}, Z$.

$$
\begin{aligned}
W_{i}^{m}\left(T_{i}, T_{j}\right) & \left.=\Omega_{i}\left[(\alpha-2 \underline{c})-\left(T_{i}+T_{j}\right)\right]^{2}\right\} / 8 \beta \\
& +T_{i}\left[(\alpha-2 \underline{c})-\left(T_{i}+T_{j}\right)\right] / 2 \beta .
\end{aligned}
$$

From $\partial W_{i}^{m}\left(T_{i}, T_{j}\right) / \partial T_{i}=0$, it is obtained that

$$
T_{i}^{m}\left(T_{j}\right)=\frac{(2-\Omega)(-2 c)}{4-\Omega}-\frac{2-\Omega}{4-\Omega} T_{j}
$$

where $\Omega_{\mathrm{i}}=\Sigma_{\mathrm{i}}+2 \Theta_{\mathrm{i}}$ for $\mathrm{i}, \mathrm{j}=\mathcal{A}, Z$. The construct of $\Omega$ shows that a marginal increase in ownership affects tax polices in the same direction as that of demand but to a larger extent. ${ }^{13}$ The equilibrium tax rates $\left(T_{\mathscr{A}}^{m}, T_{Z}^{m}\right)$ are given by

12. $X_{i}^{m d}\left(T_{i}, T_{j}\right)$ is defined by $\alpha-\left(\beta / \Sigma_{i}\right) X_{i}^{m d}\left(T_{i}, T_{j}\right)=P\left[X^{m}\left(T_{i}, T_{j}\right)\right]$.

13. There is another difference between the effect of demand and that of ownership. Any changes in ownership obey the constraint $\Theta_{i}+\Theta_{j}=1$ whereas $\Sigma_{i}$ and $\Sigma_{j}$ do not need to be constrained to add up to 1 unless these two countries are the only demanders for the product. 


$$
\mathrm{T}_{\mathrm{i}}{ }^{\mathrm{m}}=\frac{(2-\Omega)}{6-\Omega-\Omega}(-2 \underline{\mathrm{c}})
$$

for $\mathrm{i}, \mathrm{j}=\mathcal{A}, Z,{ }^{14}$ From (14) and (16), country i's welfare at the Cournot equilibrium tax rates are given by

$$
W_{i}{ }^{m}\left(T_{i}{ }^{m}, T_{j}^{m}\right)=\Upsilon\left(\Sigma_{i}, \Sigma_{j}, \Theta_{i}, \Theta_{j}\right)(-2 \underline{c})^{2}
$$

where

$$
\begin{aligned}
& \Upsilon\left(\Sigma_{i}, \Sigma_{j}, \Theta_{i}, \Theta_{j}\right)=\frac{4-\Omega}{2(6-\Omega-\Omega)^{2}} \\
& \Omega_{i}=\Sigma_{i}+2 \Theta_{i} \text { and } \Omega_{j}=\Sigma_{j}+2 \Theta_{j}
\end{aligned}
$$

for $\mathrm{i}, \mathrm{j}=\mathcal{A}, Z$. Obviously, $\Upsilon\left(\Sigma_{\mathrm{i}}, \Sigma_{\mathrm{j}}, \Theta_{\mathrm{i}}, \Theta_{\mathrm{j}}\right)>0$.

For welfare to increase with the birth of $M N E, W_{i}{ }^{m}\left(T_{i}{ }^{m}, T_{j}{ }^{m}\right)>W_{i}{ }^{c}\left(T_{i}{ }^{c}, T_{j}^{c}\right)$ should hold. A simple algebraic rearrangement using (8) and (17) results in the following Theorem 5 . Also in Theorem 5 is presented the condition to examine from the welfare point of view if the emergence of $\mathrm{MNE}$ is harder to justify or not.

Theorem 5: Let $\Lambda\left(\Sigma_{i}, \Sigma_{j}, \Theta_{i}, \Theta_{j}\right)=\sqrt{\Upsilon\left(\Sigma_{i}, \Sigma_{j}, \Theta_{i}, \Theta_{j}\right) / \Psi\left(\Sigma_{i}, \Sigma_{j}\right)}$. The fol lowing two results hold:

(i) the condition on cost difference needed to justify the emergence of $M N E$ on welfare grounds is given by

$$
\Delta \mathrm{C}>\left[1-\Lambda\left(\Sigma_{\mathrm{i}}, \Sigma_{\mathrm{j}}, \Theta_{\mathrm{i}}, \Theta_{\mathrm{j}}\right)\right](-2 \underline{\mathrm{c}})
$$

(ii) it is harder to justify the emergence of M NE on welfare grounds if and only if

$$
1-\left(\Sigma_{i}, \Sigma_{j}, \Theta_{i}, \Theta_{j}\right)>\left[\Gamma\left(\Sigma_{i}, \Theta_{i}\right)-1\right] / \Gamma\left(\Sigma_{i}, \Theta_{i}\right)
$$

where $\Gamma\left(\Sigma_{\mathrm{i}}, \Theta_{\mathrm{i}}\right)$ is defined in Theorem $2, \Psi\left(\Sigma_{\mathrm{i}}, \Sigma_{\mathrm{j}}\right)$ in (9), and $\Upsilon\left(\Sigma_{\mathrm{i}}, \Sigma_{\mathrm{j}}, \Theta_{\mathrm{i}}, \Theta_{\mathrm{j}}\right)$ in (18).

14. It is interesting to note that the equilibrium tax rate $T_{i}{ }^{m}$ in the presence of the M NE depends on $\Sigma_{\mathrm{i}}, \Sigma_{\mathrm{j}}, \Theta_{\mathrm{i}}$ and $\Theta_{\mathrm{j}}$ only in the form of $\Sigma_{\mathrm{i}}+2 \Theta_{\mathrm{i}}$ and $\Sigma_{\mathrm{j}}+2 \Theta_{\mathrm{j}}$. Therefore, demand and ownership affect tax policies only in a combined and not separate manner. 
Proof: A simple algebraic rearrangement establishes that $W_{i}{ }^{m}\left(T_{i}{ }^{m}, T_{j}^{m}\right)>$ $W_{i}{ }^{c}\left(T_{i}{ }^{c}, T_{j}{ }^{c}\right)$ is equivalent to $\Delta c>\left[1-\Lambda\left(\Sigma_{i}, \Sigma_{j}, \Theta_{i}, \Theta_{j}\right)\right](\alpha-2 c)$, which proves (i). From Theorem 2 , the case in which the birth of MNE improves welfare is characterized by the condition $\Delta c>(\alpha-2 c),\left[\Gamma\left(\Sigma_{i}, \Theta_{i}\right)-1\right] / \Gamma\left(\Sigma_{i}, \Theta_{i}\right)$. Compar ing this condition with the condition in (i) gives (ii).

For the analysis of this section to gain substance, it is necessary that $\Lambda\left(\Sigma_{\mathrm{i}}, \Sigma_{\mathrm{j}}, \Theta_{\mathrm{i}}, \Theta_{\mathrm{j}}\right)<1$. Furthermore, in order to show if the M NE is harder to justify on welfare grounds in the presence of strategic taxation than without it, it is required that $\left[\Gamma\left(\Sigma_{i}, \Theta_{i}\right)-1\right] / \Gamma\left(\Sigma_{i}, \Theta_{i}\right)$ in Theorem 2 be compared with $1-\Lambda\left(\Sigma_{i}, \Sigma_{j}, \Theta_{i}, \Theta_{j}\right)$. However, it is only cumbersome without allowing richer insights to work with the general case in order to draw implications from the model. In what follows, therefore, the argument will focus on the symmetric case: namely, $\Sigma_{i}=\Sigma_{j}=1 / 2$ and $\Theta_{i}=\Theta_{j}=1 / 2$. This symmetric example is entirely sufficient to render the implications of strategic tax policy.

The following Theorem 6 characterizes the Cournot equilibrium in terms of tax rates and welfare level with and without the M NE for the symmetric case.

Theorem 6: Suppose that the two countries are symmetric in terms of demand and ownership: that is, $\Sigma_{i}=\Sigma_{j}=1 / 2$ and $\Theta_{i}=\Theta_{j}=1 / 2 .{ }^{15}$ Then

(i) $T_{i}^{c}=-[\alpha-(c+\underline{c})] / 12$

(ii) $T_{i}^{m}=(\alpha-2 \underline{c}) / 6$

(iii) $W_{i}^{c}\left(T_{i}^{c}, T_{j}^{c}\right)=\left[\alpha-\left(c_{-}+c\right)\right]^{2} / 4 \beta$

(iv) $W_{i}^{m}\left(T_{i}^{m}, T_{j}^{m}\right)=5(\alpha-2 \underline{c})^{2} / 36 \beta$

where $\mathrm{i}, \mathrm{j}=\mathcal{A}, Z$.

Proof: Straightforward from (7), (8), (16) and (17).

Theorem 6 suggests that taxing incentives are larger with the M NE than without it as $T_{i}^{m}=(\alpha-2 \underline{c}) / 6>0>-[\alpha-(c+\underline{c})] / 12=T_{i}^{c}$ if the two countries are symmetric in demand and ownership. ${ }^{16} \mathrm{M}$ ore specifically, the incentives for the countries to tax are entirely different depending on the presence of

15. In this case, $\Omega_{\mathrm{i}}=\Omega_{\mathrm{j}}=3 / 2$.

16. In fact, as the economic variables in this model are continuous in tax rates, which in turn are continuous in demand and ownership parameters, this result can generalize to the cases in which the two countries are similar in demand and ownership. 
MNE. It should be stressed that a country that subsidizes its firm in the absence of MNE taxes the MNE's production process taking place in its jurisdiction. This clearly suggests that M NEs that improve production efficiency are likely to be subject to heavier taxation. This issue will be brought up again at the end of this section. For the symmetric case, welfare assessment is given in the following Theorem 7 .

Theorem 7: Suppose that the two countries are symmetric in terms of both demand and ownership: that is, $\Sigma_{\mathrm{i}}=\Sigma_{\mathrm{j}}=1 / 2$ and $\Theta_{\mathrm{i}}=\Theta_{\mathrm{j}}=1 / 2$. F or $\mathrm{i}, \mathrm{j}=\mathcal{A}, Z$, then, $W_{i}{ }^{m}\left(T_{i}{ }^{m}, T_{j}^{m}\right)>W_{i}^{c}\left(T_{i}^{c}, T_{j}^{c}\right)$ if and only if $\Delta c>(\alpha-2 \underline{c})(1-\Lambda(1 / 2,1 / 2$, $1 / 2,1 / 2)$ where $\Lambda(1 / 2,1 / 2,1 / 2,1 / 2)=\div 5 / 3$.

Proof: By definition, $W_{i}{ }^{m}\left(T_{i}{ }^{m}, T_{j}{ }^{m}\right)>W_{i}{ }^{c}\left(T_{i}{ }^{c}, T_{j}{ }^{c}\right)$ is equivalent to $[\alpha-(c+$ c) $] /(\alpha-2 \underline{c})<\div 5 / 3$. Rearranging terms completes the proof.

What happens to the economic condition that justifies the birth of M NE with taxes in the model? In the absence of strategic taxation, under symmetry, it can shown in Theorem 2 that $[\Gamma(1 / 2,1 / 2)-1] / \Gamma(1 / 2,1 / 2)=1-$ $3 \div 6 / 8$ : that is, the cost difference that makes the emergence of the M NE socially desirable is $\Delta c>(\alpha-2 c)(1-3 \div 6 / 8)$. On the other hand, in the presence of strategic taxation, $\Lambda(1 / 2,1 / 2,1 / 2,1 / 2)=\div 5 / 3$ : that is, $\Delta c>$ $(\alpha-2 \underline{c})(1-\div 5 / 3)$ is needed for the emergence of M NE to be justified on welfare grounds. $N$ ote that $1-\Lambda(1 / 2,1 / 2,1 / 2,1 / 2)>[\Gamma(1 / 2,1 / 2)-L] / \Gamma(1 / 2,1 / 2)$ because $1-5 \div 3>1-3 \div 6 / 8$. That is, the condition presented in Theorem 5 , the condition needed for the birth of the MNE to improve welfare, does not hold trivially. In this sense, it is true that the emergence of MNE is harder to justify on welfare grounds in the presence of strategic taxation that in its absence. ${ }^{17}$

Theorem 7 captures the inefficiency caused by the countries' strategic taxing of the MNE's profitable business conducted in their jurisdictions. This observation is based on the fact that the birth of the M NE changes the environment in which governments make tax policies. By nature, the presence of an M NE involves more than one governments as tax authorities and

17. As mentioned in footnote 16 , invoking the continuity of the economic variables in tax rates, and of tax rates in demand and ownership parameters, Theorem 7 can generalize to the cases in which the two countries are similar in demand and ownership. 
creates a situation with a public good: that is, a country subsidizing the M NE's activity shares the benefit with other countries holding stakes at the MNE while a country taxing the MNE's activity shifts part of the distortion it causes to other countries. This leads tax authorities to a circumstance in which they make a strategic use of the M NE's special status. Similar arguments are found in Huizinga [1992] and Ahn and Park [1995] about the strategic expenditure expending of an M NE's $R \& D$. In these literature, it is shown that tax authorities are parsimonious about an $M N E$ 'S $R \& D$ expenditure expending and thus $R \& D$ fails to achieve the optimal level. In general, tax authorities have an incentive to tax more heavily an MNE's efficiency enhancing activity than an optimum suggests, and this kind of strategic taxing incentive grows stronger with the emergence of an M NE. ${ }^{18}$

\section{Concluding Remarks}

This paper explored the economic rationale for an M NE from an efficiency viewpoint with the consumption side of an economy being properly considered in welfare assessment. It was shown that the promotion of production efficiency is not sufficient to guarantee the economic desirability of an $M N E$. This paper, therefore, warns that it is very much misleading to envisage the emergence of an M NE as economically desirable simply because it increases production efficiency. The economic consequence of an M NE ought to be placed under a proper examination taking account of the consumption side of an economy.

The rationalization for an MNE is harder to come by when taxation is incorporated to the model. This adverse finding about M NEs rests on the inefficiency that is created by the countries' incentive to strategically tax the $M N E$ 's efficiency promoting activities. Based on this observation, this paper suggests a need for tax coordination between tax authorities to get M NES out of unduly tax burden with a view to creating an environment favorable to M NEs that improve welfare in a number of countries.

18. As suggested in Ahn and Park [1995], sub-optimality due to strategic taxing on an $M N E$ 's economic activities can be rectified if non-myopic tax authorities engage in a long-term relationship. 


\section{References}

Ahn, Sukwhan, and Park, Jungsoo [1995], "Strategic Expenditure Expending of a Multinational Corporation's Externality-E mitting R\&D," M imeograph.

Behrman, Jack N. [1972], The Role of International Companies in Latin Ame rica: Autos and Petrochemicals, Lexington, M A: Lexington Books.

B rander, James A. and Spencer, Barbara J. [1985], "Export Subsidies and International M arket Share Rivalry," Journal of I nternational E conom ics, 18; pp.83-100.

Dunning, John, H. [1992], M ultinational Enterprises and the Global E cono my, Addison Wesley.

Huizinga, Har ry [1991], "National Tax Policies towards Product-Innovating M ultinational Enterprises," Journal of Public Economics, 44, 1; pp. 1-14. Huizinga, Harry [1992], "The Tax Treatment of $R \& D$ Expenditures of M ultinational Enterprises," Journal of Public E conomics, Vol. 47, No. 3; pp. 343-359.

Kreps, David M . [1990], A Course in M icroeconomic Theor y, Princeton University Press. 